\title{
Effectiveness of Cervical Medial Branch Blocks in Chronic Neck Pain: A Prospective Outcome Study
}

\author{
Laxmaiah Manchikanti, MD, Kavita N. Manchikanti, Kim Damron, RN, and Vidyasagar Pampati, MSc
}

\begin{abstract}
Background: The high prevalence of persistent neck pain due to involvement of cervical facet joints has been described in controlled studies. Therapeutic interventions utilized in managing chronic neck pain of facet joint origin include intraarticular injections, medial branch nerve blocks, and neurolysis of medial branch nerves by means of radiofrequency.

Objective: The objective of this prospective evaluation was to determine the clinical effectiveness of cervical medial branch blocks for therapeutic purposes.

Design: A prospective, non-randomized, outcome study.

Methods: One hundred consecutive patients meeting the diagnostic criteria of fac-
\end{abstract}

The prevalence of persistent neck pain due to involvement of cervical facet joints has been described in controlled studies as varying from $54 \%$ to $67 \%$ based on types of population and settings studied (1-5). Even though evidence is lacking for the diagnosis of cervical facet syndrome, a preponderance of evidence supports the existence of cervical facet joint pain (1-16).

As with the epidemiology and clinical significance of facet joint pain, significant controversy surrounds various treatments utilized in the management of chronic neck pain arising from cervical facet joints (6, 17-19). Therapeutic benefit for facet joint pain has been reported with three types of interventions. These include intraarticular injections, medial branch nerve blocks, and neurolysis of medial branch nerves by means of ra-

From Pain Management Center of Paducah, Paducah, Kentucky. Address Correspondence: Laxmaiah Manchikanti, MD, 2831 Lone Oak Road, Paducah, Kentucky 42003.

E-mail: drm@apex.net

Support:There was no external funding in preparation of this manuscript

Conflict of Interest: None et joint pain by means of comparative, controlled diagnostic blocks were included in this evaluation. All medial branch blocks were performed in a sterile operating room under fluoroscopic visualization with mild sedation with midazolam and/or fentanyl. Statistical methods incorporated intent-totreat analysis.

Outcome Measures: Numeric pain scores, Oswestry Disability Index, work status, and Pain Patient Profile ( $\left.\mathrm{P}-3{ }^{\circledR}\right)$. Significant pain relief was defined as average relief of $50 \%$ or greater.

Results: The results showed significant differences in numeric pain scores and significant pain relief ( $50 \%$ or greater) at 3 months, 6 months, and 12 months, com- pared to baseline measurements. Functional improvement was demonstrated at 12 months from baseline. There was significant improvement with increase in employment among the patients eligible for employment (employed and unemployed) from baseline to 12 months, and improved psychological functioning.

Conclusion: Cervical medial branch blocks were an effective modality of treatment in managing chronic neck pain secondary to facet joint involvement confirmed by controlled, comparative local anesthetic blocks.

Keywords: Chronic neck pain, facet joint pain, medial branch blocks, comparative controlled local anesthetic blocks diofrequency. The long-term therapeutic benefit of intraarticular injections of facet joints has been poor $(6,11)$. The evidence for long-term benefits of medial branch nerve blocks is preliminary $(6,12)$; and radiofrequency neurotomy is supported with moderate evidence for long-term relief $(13-15,17)$ with some contradictory reports $(18,19)$.

There is a paucity of literature on the role of therapeutic medial branch or facet joint nerve blocks in the literature. The explanation of the effectiveness of therapeutic nerve blocks may be based on the neurolytic activity of the blockade or various unknown effects of neural blockade providing relief lasting much longer than the pharmacological duration of the drugs utilized. The explanation follows the philosophy that unexplained benefits are achieved from neural blockade with overall benefit of various types of injection techniques, including pain relief outlasting by days, weeks, or months, the relatively short duration of pharmacological action of the local anesthetic and other agents used. Clear-cut explanations for these benefits, of course, are not currently available specifically for facet joint nerve blocks. It is believed that facet joint nerve blocks, similar to other nerve blocks, alter or interrupt nociceptive input, reflex mechanisms of the afferent limb, self-sustaining activity of the neuron pools and neuraxis, and the pattern of central neuronal activities (20). It may also be possible that pain relief may result from blockade of pain fibers from muscles innervated by the medial branch nerves, i.e., deep paramedian muscles. The explanations in part are based on the pharmacological and physical actions of the various drugs employed, including local anesthetics, corticosteroids, and other agents. In addition, it is believed that local anesthetics interrupt the pain-spasm cycle and reverberating nociceptor transmission; whereas corticosteroids reduce inflammation either by inhibiting the synthesis or the release of a number of pro-inflammatory substances (21-27). Local anesthetics also have been shown to produce prolonged dampening of C-fiber activity (28-30). Thus, corticosteroids may inhibit sensitized nerves by suppressing spontaneous neuron depolarization. While the scientific basis of some of these concepts, at least in part, is proven for management 
of discogenic pain, particularly with epidural injections of betamethasone and intravenous methylprednisolone $(24,31$ $34)$, there is no such explanation for therapeutic facet joint nerve blocks.

Medial branch blocks have been extensively utilized for diagnostic and prognostic purposes $(1-6,11,12,16)$ with limited use for therapeutic purposes $(6,35)$. The therapeutic role of medial branch blocks has not been evaluated in the cervical spine in randomized or controlled trials.

This prospective evaluation was undertaken to study the clinical effectiveness of cervical medial branch blocks for therapeutic purposes after the diagnosis of cervical facet joint pain was confirmed by comparative, controlled, local anesthetic blocks.

\section{Methods}

One hundred consecutive patients meeting the diagnostic criteria of facet joint pain by means of comparative, controlled diagnostic blocks and willingness to participate in this clinical evaluation as part of their continuing treatment, were included in this evaluation. No financial or other incentive was provided. The study was performed in an interventional pain management setting in private practice.

All patients were given an explanation of the purpose of this study and an opportunity for discussion. They were also advised of the associated risks and given the choice as to whether or not they wanted to participate. Informed consent was then obtained. Appropriate precautions were taken to protect the privacy and anonymity of all of the patients participating in this study.

Prior to enrollment in the therapeutic phase, patients were evaluated for facet joint pain, based on historical, clinical, and radiological evaluation. Only patients with non-specific neck pain rather than radicular pain and a duration of at least 6 months were included. Disc related pain with radicular symptoms was excluded in all patients based on radiologic or neurologic testing, lack of a neurological deficit, and lack of radicular symptoms or pain that involved predominantly the upper extremity. All patients included for the diagnosis of facet joint pain had failed conservative management, which included physical therapy, chiropractic manipulation, exercises, drug therapy, bedrest, etc.

Facet joint pain was investigated in all patients starting with diagnostic blocks using 1\% lidocaine. Patients with lidocaine-positive results were further studied using $0.25 \%$ bupivacaine on a separate occasion, usually 3 to 4 weeks after the first injection. The blocks were performed on the ipsilateral side in patients with unilateral pain or bilaterally in patients with bilateral or axial pain. Blocks were performed at a minimum of 2 nerves to block a single joint. Target joints were identified by the pain pattern, local or paramedian tenderness over the area of the facet joints, and reproduction of pain with deep pressure.

Blocks were performed with intermittent fluoroscopic visualization using a 22-gauge, 2-inch spinal needle at each of the indicated medial branches in the cervical spine. All blocks were performed by one physician (LM). Intravenous access was established and light sedation with midazolam and/or fentanyl was offered to all patients. Each facet nerve was infiltrated with $0.5 \mathrm{~mL}$ of $1 \%$ lidocaine or $0.25 \%$ bupivacaine. A positive response was defined as at least $80 \%$ reduction in pain with previously painful movements as assessed using a verbal numeric pain scale. To be considered positive, pain relief from a block had to last at least 2 hours when lidocaine was used, and for at least 3 hours, or greater than the duration of relief with lidocaine, when bupivacaine was used. Any other response was considered a negative outcome.

Patients judged to be positive for facet joint pain following controlled comparative local anesthetic blocks as described above and willing to participate in this clinical evaluation as part of their continuing treatment underwent therapeutic facet joint nerve blocks.

Inclusion criteria included diagnosis of facet joint pain by means of comparative local anesthetic blocks, patients over 18 years of age, patients with a history of chronic, function-limiting neck pain of at least 1 year duration, patients who were able to provide voluntary, written informed consent to participate in this evaluation, patients who were able to understand this evaluation, patients willing to return for follow-ups, and patients without history of recent surgical procedures within the last 3 months.

Exclusion criteria included negative or false-positive responses to controlled comparative local anesthetic blocks, heavy narcotic usage, uncontrolled major depression or uncontrolled psychiatric dis- orders, uncontrolled or acute medical illness, chronic severe conditions that could interfere with interpretation of the outcome assessment, women who were pregnant or lactating, patients unable to be positioned prone, and patients with a history of adverse reaction to local anesthetic or anti-inflammatory drugs.

All the medial branch blocks were performed utilizing a posterior approach with the patient in the prone position with a pillow under the chest and the head turned to the opposite side. The target points for medial branches were identified at the crossing points of the waists of the articular pillars - a point proximal to the origin of the articular branches and a point where the nerves have a constant relationship to the bone. Under fluoroscopic visualization, after identification of the waists of the articular pillars at the desired levels to be blocked, the medial branch block was carried out with a \#22-gauge 2-inch spinal needle, by injecting 1.0 to $2.0 \mathrm{~mL}$ of local anesthetic with or without Sarapin and/or Depo-Medrol at each level.

Therapeutic facet joint blocks were performed in accordance with Evidencebased Practice Guidelines for Interventional Techniques in the Management of Chronic Spinal Pain (6) and Local Medical Review Policy of AdminaStar Federal of Kentucky and Indiana. The guidelines and Local Medical Review Policy indicate that facet joint injections may be performed at intervals of no sooner than 1 week or, preferably, 2 weeks in the diagnostic phase.

In the therapeutic phase (after the diagnosis is established), the suggested frequency of facet joint nerve blocks should be 2 months or longer between each injection, provided that at least greater than $50 \%$ relief is obtained for 6 weeks. In the diagnostic phase, the suggested number of injections should be limited to no more than 4 times per year, whereas in the therapeutic phase, facet joint nerve blocks should be repeated only as necessary judging by the medical necessity criteria, and should be limited to a maximum of 6 times for local anesthetic and steroid blocks over a period of one year.

Based on these guidelines, after patients were enrolled in the study, each patient was evaluated and offered treatment, however, not exceeding 6 times per year in the therapeutic phase, which lasted for 1 year. Therapeutic facet joint nerve blocks were repeated based on the response to prior interventions with improvement in phys- 
ical and functional status, and only upon increased levels of pain greater than $50 \%$ level or deterioration of relief to below $50 \%$.

Data collection included demographic data, assessment of pain with numeric pain scales at baseline, 3-months, 6 months, and 12-months. Oswestry Disability Questionnaire 2.0, psychological evaluation with Pain Patient Profile (P$\left.3^{\circledR}\right)$ and work status were determined in each patient at baseline and at 12 months. The same co-interventions as needed with narcotic and non-narcotic analgesics, adjuvant analgesics, previously directed exercise program prior to enrollment, were continued in all patients. No specific physical therapy, occupational therapy, bracing, or other specific interventions were included.

Employment and work status (employed, unemployed, housewife, disabled, and retired) were determined. Only employed and unemployed patients were considered to be eligible for employment, whereas disabled patients and retired patients were considered not employable.

\section{Statistical Methods}

Data were recorded on a database using Microsoft ${ }^{\circledR}$ Access ${ }^{\circledR}$. The SPSS version 9.0 statistical package was used to generate the descriptive tables. A paired t-test was used to compare the pre- and posttreatment results, which were considered statistically significant if the $P$ value was less than 0.05 .

An intent-to-treat analysis was performed in all patients. Last follow-up data (or initial data in the case of P-3 and Oswestry which were administered initially and at the end of 12 months) were utilized in the patients who dropped out of the study due to poor response or with lack of follow-up data.

RESULtS

Patient Flow

From January 2000 to November 2001, a total of 326 patients with chronic neck pain, suspected of having pain of facet joint origin were evaluated utilizing controlled, comparative local anesthetic blocks. Of these patients, 162, after testing positive with both lidocaine and bupivacaine were considered positive for cervical facet joint pain. They were all assessed and offered the opportunity to participate in the study.

Of the 162 assessed patients, 100 agreed to participate in the evaluation. Fourteen of the 100 patients either received no treatments or were not available

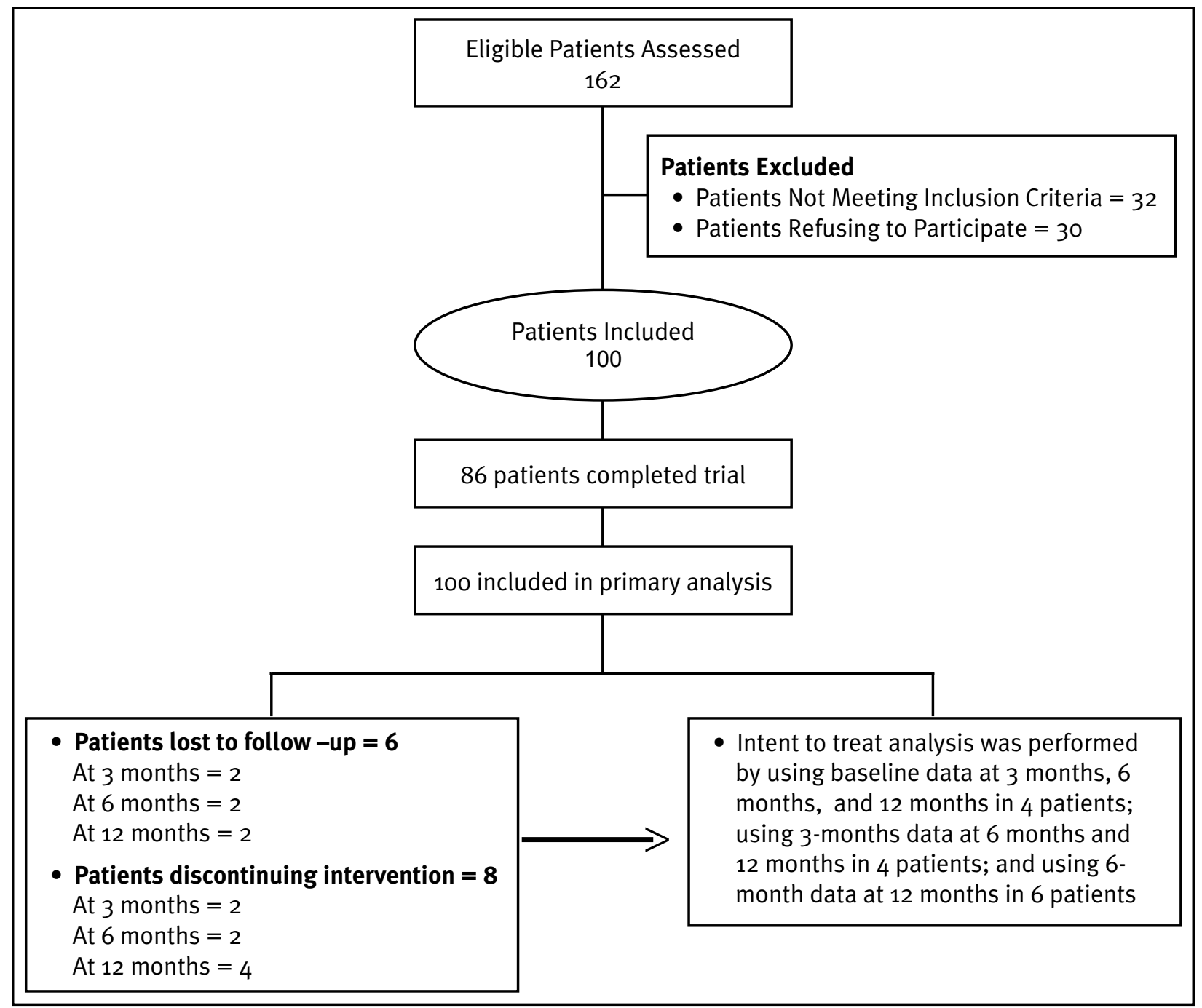

Fig 1. Schematic representation of patient flow thru evaluation at baseline to 12 months 
for follow-up by 1 year. Figure 1 illustrates the participant flow diagram.

\section{Demographic Characteristics}

Patients were predominantly female $(65 \%)$, with $($ mean $\pm S D)$ age of $43 \pm 13.6$ years, height (mean \pm SD) of $67 \pm 3.7$ inches, and weight (mean \pm SD) of $177 \pm$ 48.7 lbs. Average duration of pain (mean \pm SD) was $113 \pm 100$ months with $30 \%$ of patients reporting onset following an incident, and $23 \%$ with a history of previous surgery.

\section{Procedural Characteristics}

The total number of interventions or treatments provided for the 100 patients over a period of 1 year were 402 . The average number of treatments (mean $\pm \mathrm{SD}$ ) per patient were $4 \pm 1.2$ with a range of 1 to 5 . The average relief for each procedure was $12.2 \pm 6.1$ weeks (mean \pm SD) with a range of 0 to 106 weeks.

The number of joints involved was as follows: two joints were involved in $32 \%$ of the patients, 3 joints were involved in $64 \%$ of the patients, and 4 joints were involved in $4 \%$ of the patients. Bilateral involvement was seen in $56 \%$ of the patients.

Table 1 illustrates procedural characteristics with frequency and number of procedures. These procedures do not include the diagnostic blocks performed with lidocaine and bupivacaine prior to enrolling in the study. The relief obtained and the period during which the diagnostic blocks were performed are not included in the one year period. A total of 27 patients received 1-3 procedures over a oneyear period. Only one patient received 6 procedures.

\section{Pain Relief}

Numeric pain scale report at baseline and at 3 months, 6 months, and 12 months is illustrated in Table 2. There were significant differences with baseline values at 3, 6, and 12 months. Figure 2 shows the proportion of patients with significant relief, which was defined as greater than $50 \%$ at 3,6 , and 12 months.

\section{Outcome Measures}

Functional measures included the Oswestry Disability Index 2.0 and psychological measures included evaluation using the Pain Patient Profile (P- $\left.3{ }^{\circledR}\right)$. Employment status was also evaluated at pretreatment and 12 months.
Table 1. Therapeutic procedural characteristics over a period of one year (n-100)

\begin{tabular}{|c|c|c|c|c|}
\hline \multirow{2}{*}{$\begin{array}{c}\text { No. of Procedures in } \\
\text { one year }\end{array}$} & \multirow{2}{*}{ No. of Patients } & \multicolumn{3}{|c|}{ Duration of Pain relief in weeks (mean \pm SD) } \\
\cline { 3 - 5 } & & Per procedure & Range & Total \\
\hline 1 & 6 & $31.3 \pm 39.6$ & $0-106$ & $31.3 \pm 39.6$ \\
\hline 2 & 6 & $13.7 \pm 8.6$ & $8-44$ & $27.3 \pm 12.2$ \\
\hline 3 & 15 & $13.5 \pm 8.6$ & $9-67$ & $40.5 \pm 14.9$ \\
\hline 4 & 27 & $12.4 \pm 2.3$ & $39-62$ & $49.5 \pm 4.5$ \\
\hline 5 & 45 & $11.2 \pm 3.1$ & $40-71$ & $55.8 \pm 6.9$ \\
\hline 6 & 1 & 8 & $49-49$ & 49 \\
\hline
\end{tabular}

\begin{tabular}{l}
\hline Table 2. Numeric pain scale scores $(n=100)$ \\
\begin{tabular}{|c|c|}
\hline & Mean \pm SD \\
\hline Baseline & $8.0 \pm 0.9$ \\
\hline 3 months & $3.4^{\star} \pm 0.8$ \\
\hline 6 months & $3.4^{\star} \pm 0.8$ \\
\hline 12 months & $3.5^{\star} \pm 0.8$ \\
\hline
\end{tabular}
\end{tabular}

${ }^{*}$ Indicates significant difference with baseline values $(p<0.001)$

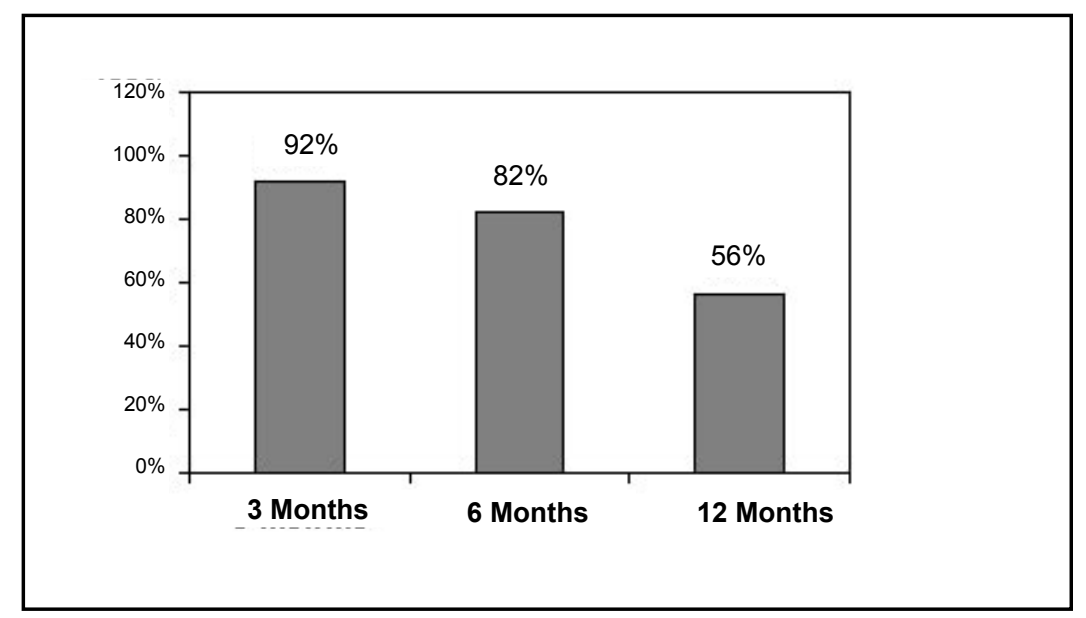

Fig 2. Proportion of patients with significant relief $(>=50 \%)(n=100)$

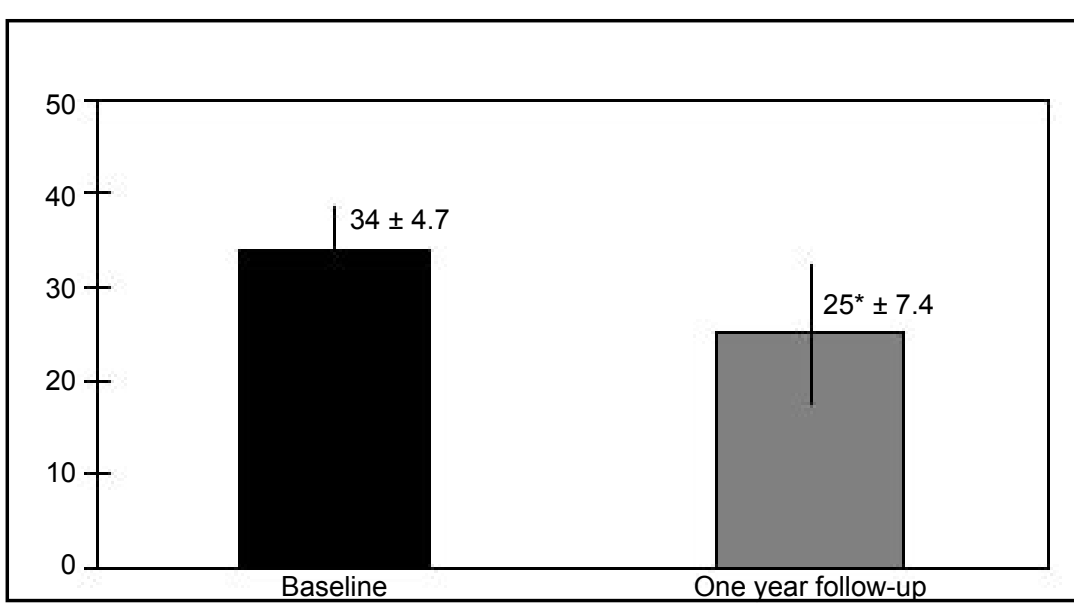

* Indicates significant difference with baseline values $(p<0.001)$

Fig 3. Functional measurement by Oswestry Disability Index $(n=100)$ 


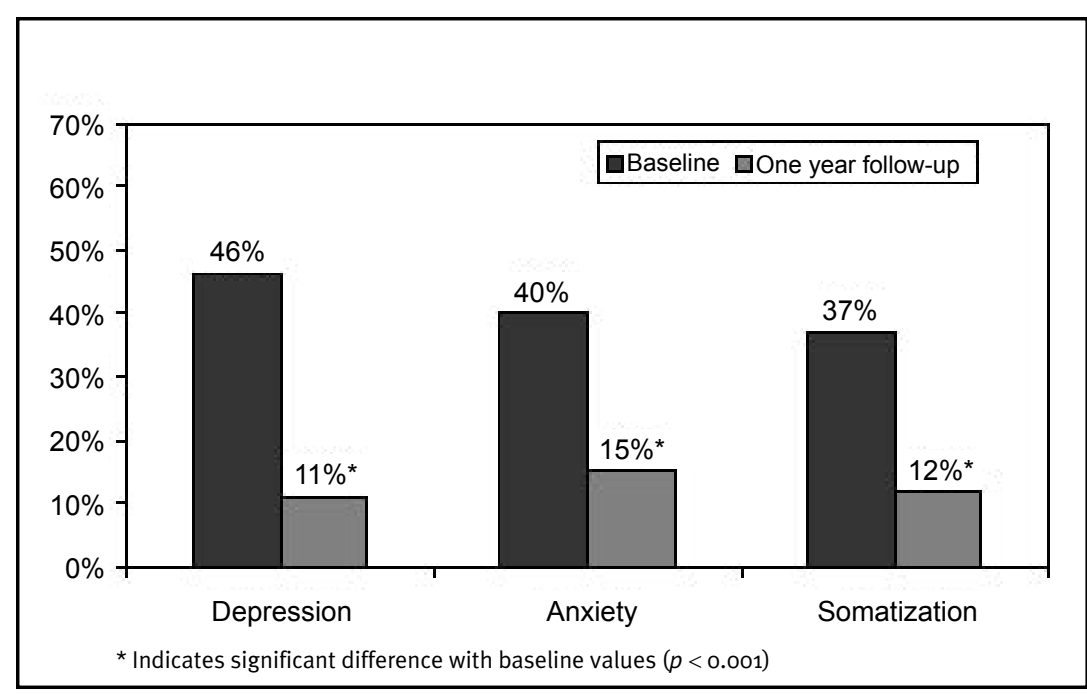

Fig 4. Illustration of psychological diagnosis by $P-3$ values $(n=100)$

Table 3. Analysis of psychological outcome measurements $(n=100)$ by P3 evaluation scores (mean $\pm S D$ )

\begin{tabular}{|l|c|c|}
\hline & Baseline & 12 months \\
\hline Depression & $52 \pm 9.4$ & $45^{\star} \pm 8.6$ \\
\hline Anxiety & $53 \pm 10.7$ & $46^{\star} \pm 9.8$ \\
\hline Somatization & $53 \pm 8.7$ & $46^{\star} \pm 10.8$ \\
\hline
\end{tabular}

* Indicates significant difference with Baseline values $(p<0.001)$

Table 4. Employment Status $(n=100)$

\begin{tabular}{|l|c|c|}
\hline & Baseline & 12 months \\
\hline Employed & $19 \%$ & $41 \%$ * \\
\hline Unemployed & $30 \%$ & $10 \%$ \\
\hline Housewife & $2 \%$ & $2 \%$ \\
\hline Disabled & $23 \%$ & $21 \%$ \\
\hline Over 65 & $26 \%$ & $26 \%$ \\
\hline
\end{tabular}

* Indicates significant difference with Baseline values $(p<0.001)$

Figure 3 illustrates functional measures as assessed by the Oswestry Disability Index 2.0. Figure 4 and Table 3 illustrate findings of the psychological evaluation. Psychological diagnosis was made based on scores of the $\mathrm{P}-3 \otimes$ evaluation. Depression was diagnosed with scores of 55 or higher, whereas scores of 56 or higher for anxiety and somatization represented the diagnosis. Table 3 shows the changes in the psychological status from baseline to 12 months. Figure 4 illustrates the proportion of patients with a diagnosis of depression, anxiety, and somatization at baseline and post-treatment. There was significant improvement noted in all aspects.
Table 4 shows employment status. Among the patients eligible for employment (employed and unemployed) there was significant improvement with increase in employment.

\section{Adverse Events}

There were no adverse events reported during this study.

\section{DisCUSSION}

This evaluation showed significant pain relief in $92 \%$ of the patients at 3 months, $82 \%$ at 6 months, and $56 \%$ at 12 months. Numeric pain scale assessment also showed significant improvement at 3 , 6 , and 12 months. This study demonstrated that there was significant improvement in functional status, psychological status, and work status. The results are important in that the patients in this study represented patients who have failed multiple non-interventional conservative modalities of management. These observations demonstrate the potential usefulness of cervical facet joint blocks in the management of chronic neck pain, where the diagnosis has been confirmed by controlled, comparative local anesthetic blocks.

The current study is the first to have treated patients with facet joint pain confirmed with controlled diagnostic blocks utilizing therapeutic medial branch blocks. In addition, the study utilized objective outcome measures.

This study may be criticized for nonrandomization, not including a placebo group and for providing multiple procedures. Considering the difficulties in recruiting for a double-blind trial, the authors decided to perform a prospective evaluation prior to embarking on a randomized, double-blind trial. Further, without non-randomized reports on this subject, a prospective trial was the first step. In addition, the issues of ethics, feasibility, cost, and reliability pose challenges to a double-blind trial, which theoretically presents the gold standard (36-43).

Multiple analyses by Concato et al (44) and others have reinforced the value of prospective trials. Concato et al (44) analyzed numerous reports for five clinical topics, and found that well-designed observational studies do not systematically overestimate the magnitude of effects of treatments as compared with those in randomized, controlled trials on the same topic. Supporting a prospective trial is not to undermine the importance of a randomized, double-blinded, controlled study. Indeed, flaws can exist in a study design or analysis, both in non-randomized and randomized trials (43-49).

The study may also be criticized for lack of outside third party review. However, the physicians involved in the evaluation included not only the treating physician, but also a physician who was not involved in providing care to these patients. Further, multiple outcome measures were utilized rather than only subjective measures.

Multiple procedures were provided, as most interventional procedures, including epidural steroids and facet joint interventions provide short-term relief with the first treatment. Long-term im- 
provement is only feasible with repeat interventions. The concept of multiple procedures has been a common phenomenon with interventional techniques $(6,50-53)$. One may also criticize the fact that multiple procedures were performed at different levels, which is not cost effective. While blocks were performed in the majority of patients at three levels, all the patients were only billed for two levels, either unilateral or bilateral. The criticism may also be forwarded that a total of 6 blocks were performed in each patient. However, there were only an average (mean \pm SD) of $4 \pm 1.2$ blocks per patient per joint in the therapeutic phase during one year. Only one patient was treated with 6 therapeutic blocks in one year. The diagnostic phase, which lasted 1 to 3 months, is not included in this evaluation. Thus, if one adds diagnostic blocks to the therapeutic blocks, the average number of blocks would be 6 for a period of 14 to 15 months. According to evidence-based guidelines (6) and Local Medical Review Policy of AdminaStar Federal of Kentucky and Indiana, based on the response, 4 to 6 therapeutic blocks over a period of one year are well within reasonable limits. Thus, these data should be interpreted in interventional pain management settings, using appropriate billing practices within the guidelines established, billing for a maximum of 2 joints ( 3 medial branches to block 2 joints or bill 2 joints) during each intervention.

In summary, this prospective trial showed that therapeutic facet joint nerve blocks reduced pain and improved functional status with return to work in a significant number of patients who were eligible to return to work.

\section{ConcLusion}

Cervical medial branch blocks were an effective modality of treatment in managing chronic neck pain secondary to facet joint involvement confirmed by controlled, comparative local anesthetic blocks. Medial branch blocks were effective in providing pain relief, improvement in functional status, improvement in overall psychological status, and return to work, without adverse effects.

\section{ACKNOWLEDGMENTS}

The authors wish to thank Tonie Hatton, transcriptionist; Carla D. McManus, Sheila Jackson, RN, Doris E. Brandon, CST, Sue R. Wilson, ORT, and Vic- toria L. Hicks, ORT; for their assistance in preparation of this manuscript.

\section{Author Affiliation:}

Laxmaiah Manchikanti, MD

Medical Director

Pain Management Center of Paducah

2831 Lone Oak Road

Paducah, Kentucky 42003

E-mail: drm@apex.net.

Kavita N. Manchikanti

Research Assistant

Pain Management Center of Paducah

2831 Lone Oak Road

Paducah, Kentucky 42003

\section{Kim S. Damron, RN}

Nursing Administrator

Pain Management Center of Paducah

2831 Lone Oak Road

Paducah, Kentucky 42003

E-mail: kim@thepainmd.com

\section{Vidyasagar Pampati, MSc}

Statistician

Pain Management Center of Paducah

2831 Lone Oak Road

Paducah, Kentucky 42003

E-mail: sagar@thepainmd.com

\section{REFERENCES}

1. Barnsley L, Lord SM, Wallis BJ et al. The prevalence of chronic cervical zygapophyseal joint pain after whiplash. Spine 1995; 20:20-26.

2. Lord SM, Barnsley L, Wallis BJ et al. Chronic cervical zygapophysial joint pain with whiplash: A placebo-controlled prevalence study. Spine 1996; 21:1737-1745.

3. Manchikanti L, Singh V, Rivera J et al. Prevalence of cervical facet joint pain in chronic neck pain. Pain Physician 2002; 5:243249.

4. Manchikanti L, Singh V, Pampati S et al. Is there correlation of facet joint pain in lumbar and cervical spine? Pain Physician 2002; 5:365-371.

5. Bogduk N. International spinal injection society guidelines for the performance of spinal injection procedures. Part 1. Zygapophysial joint blocks. Clin J Pain 1997; 13:285-302.

6. Manchikanti L, Staats P, Singh V et al. Evidence-based practice guidelines for interventional techniques in the management of chronic spinal pain. Pain Physician 2003; 6:3-80.

7. Fukui S, Ohseto K, Shiotani M et al. Referred pain distribution of the cervical zygapophyseal joints and cervical dorsal rami. Pain 1996; 68:79-83.

8. Dwyer A, Aprill C, Bogduk N. Cervical zygapophyseal joint pain patterns: A study in normal volunteers. Spine 1990; 6:453-
457.

9. Aprill C, Dwyer A, Bogduk N. The prevalence of cervical zygapophyseal joint pain patterns II: A clinical evaluation. Spine 1990; 6:458-461.

10. Pawl RP. Headache, cervical spondylosis, and anterior cervical fusion. Surg Ann 1977; 9:391-498.

11. Barnsley L, Lord SM, Wallis BJ et al. Lack of effect of intra-articular corticosteroids for chronic pain in the cervical zygapophyseal joints. N Engl J Med 1994; 330:10471050.

12. Barnsley L, Bogduk N. Medial branch blocks are specific for the diagnosis of cervical zygapophyseal joint pain. Reg Anesth 1993; 18:343-350.

13. Lord SM, Barnsley L, Bogduk N. Percutaneous radiofrequency neurotomy in the treatment of cervical zygapophyseal joint pain: a caution. Neurosurgery 1995; 35: 732-739.

14. Sapir D, Gorup JM. Radiofrequency medial branch neurotomy in litigant and nonlitigant patients with cervical whiplash. Spine 2001; 26:E268-E273.

15. McDonald GJ, Lord SM, Bogduk N. Longterm follow-up of patients treated with cervical radiofrequency neurotomy for chronic neck pain. Neurosurgery 1999; 45:61-68.

16. Boswell MV, Singh V, Staats PS et al. Accuracy of precision diagnostic blocks in the diagnosis of chronic spinal pain of facet or zygapophysial joint origin. Pain Physician 2003; 6:449-456.

17. Manchikanti L, Singh V, Vilims BD et al. Medial branch neurotomy in management of chronic spinal pain: Systematic review of the evidence. Pain Physician 2002; 5 : 405-418.

18. Geurts JW, van Wijk RM, Stolker RJ et al. Efficacy of radiofrequency procedures for the treatment of spinal pain: A systematic review of randomized clinical trials. $R e g$ Anesth Pain Med 2001; 26:394-400.

19. Niemistö L, Kalso E, Malmivaara A et al. Radiofrequency denervation for neck and back pain: A systematic review within the framework of the Cochrane Collaboration Back Review Group. Spine 2003; 28:187788.

20. Fox AJ, Melzack R. Transcutaneous electrical stimulation to acupuncture. Comparison of treatment of low back pain. Pain 1976; 2:141-148.

21. Devor M, Govrin-Lippmann R, Raber P. Corticosteroids suppress ectopic neural discharges originating in experimental neuromas. Pain 1985; 22:127-137.

22. Johansson A, Hao J, Sjolund B. Local corticosteroid application blocks transmission in normal nociceptor C-fibers. Acta Anaesthesiol Scand 1990; 34:335-338.

23. Faber LE, Wakim NG, Duhring JL. Evolving concepts in the mechanism of steroid action: Current developments. Am J Obstet Gynecol 1987; 156:1449-1458. 
24. Olmarker K, Byrod G, Cornefijord M et al. Effects of methylprednisolone on nucleus pulposus-induced nerve root injury. Spine 1994; 19:1803-1808.

25. Nicol GD, Klingberg DK, Vasko MR. Prostaglandin E2 enhances calcium conductance and stimulates release of substance $P$ in avian sensory neurons. J Neurosci 1992; 12:1917-1927.

26. Hua SY, Chen YZ. Membrane receptor-mediated electrophysiological effects of glucocorticoid on mammalian neurons. Endocrinology 1989; 124:687-691.

27. Fowler RJ, Blackwell GJ. Anti-inflammatory steroid induced biosynthesis of a phospholipase A2 inhibitor which prevents prostaglandin generation. Nature 1979; 278:456-459.

28. Bonica JJ, Backup PH, Anderson CE. Peridural block, an analysis of 3,637 cases. A review. Anesthesiology 1957; 18:723-734.

29. Fink BR, Cairns AM. Differential use-dependent (frequency-dependent) effects in single mammalian axons: Data and clinical considerations. Anesthesiology 1987; 67: 477-484.

30. Li Yue-Ming, Wingrove DE, Too HP et al. Local anesthetics inhibit substance $P$ binding and evoked increases in intracellular $\mathrm{Ca}_{2+}$. Anesthesiology 1995; 82:166-173.

31. Lee HM, Weinstein JN, Meller ST et al. The role of steroids and their effects on phospholipase $A_{2}$. An animal model of radiculopathy. Spine 1998; 23:1191-1196.

32. Minamide A, Tamaki T, Hashizume $\mathrm{H}$ et al. Effects of steroids and lipopolysaccharide on spontaneous resorption of herniated intervertebral discs. An experience study in the rabbit. Spine 1998; 23:870-876.
33. Kingery WS, Castellote JM, Maze M. Methylprednisolone prevents the development of autotomy and neuropathic edema in rats, but has no effect on nociceptive thresholds. Pain 1999; 80:555-566.

34. Hayashi N, Weinstein JN, Meller ST et al. The effect of epidural injection of betamethasone or bupivacaine in a rat model of lumbar radiculopathy. Spine 1998; 23: 877-885.

35. Manchikanti L, Pampati V, Bakhit CE et al. Effectiveness of lumbar facet joint nerve blocks in chronic low back pain: A randomized clinical trial. Pain Physician 2001; 4: 101-117.

36. Manchikanti L, Heavner J, Racz GB et al. Methods for evidence synthesis in interventional pain management. Pain Physician 2003; 6:89-111.

37. Turner JA, Loeser JD, Bell KG. Spinal cord stimulation for chronic low back pain. A systematic literature synthesis. Neurosurgery 1995; 37:1088-1098.

38. Weinstein JN. The tortoise and the hare. Is there a place in spine surgery for randomized trials? Spine 1999; 23:2548-2549.

39. Winter RB. The prospective, randomized, controlled clinical trial in spine surgery. Fact or fiction? Spine 1999; 23:2550-2552.

40. Carey TS. Randomized controlled trials in surgery. An essential component of scientific progress. Spine 1999; 23:2553-2555.

41. Fairbank J. Randomized controlled trials in the surgical management of spinal problems. Spine 1999; 23:2556-2563.

42. Tosteson TD. Point of view. Spine 1999; 24:2562-2563.

43. Lenrow DA, Chou LH. Randomized con- trolled trials in interventional spine: perils and pitfalls. Pain Physician 2003; 6:8388.

44. Concato J, Shah N, Horwitz RI. Randomized, controlled trials, observational studies, and the hierarchy of research designs. N Engl J Med 2000; 342:1887-1892.

45. Pocock SJ, Elbourne DR. Randomized trails or observational tribulations? New Engl J Med 2000; 342;1907-1909.

46. Kunz R, Khan KS, Neumayer H. Observational studies and randomized trials. New Engl J Med 2000; 343:1194.

47. Sacks HS. Observational studies and randomized trials. New Engl J Med 2000; 343: 1195 .

48. Liu PY, Anderson G, Crowley JJ. Observational studies and randomized trials. New Engl J Med 2000; 343:1195.

49. Friedman HS. Observational studies and randomized trials. N Engl J Med 2000; 343:1195-1996.

50. Carrette S, Leclaire R, Marcoux S et al. Epidural corticosteroid injections for sciatica due to herniated nucleus pulposus. $N$ Engl J Med 1997; 336:1634-1640.

51. Carrette S, Marcoux S, Truchon R et al. A controlled trial of corticosteroid injections into facet joints for chronic low back pain. N Engl J Med 1991; 325:1002-1007.

52. Boswell MV, Hansen HC, Trescot AM et al. Epidural steroids in the management of chronic spinal pain and radiculopathy. Pain Physician 2003; 6:319-334.

53. Riew KD, Yin Y, Gilula L et al. The effect of nerve root injections on the need for operative treatment of lumbar radicular pain. J Bone Joint Surg 2000; 82A:1589-1593. 
